\title{
Redox Active Ordered Arrays via Metal Initiated Self-Assembly of Terpyridine Based Ligands ${ }^{\dagger}$
}

\author{
Diego J. Díaz, Stefan Bernhard, Gregory D. Storrier, and Héctor D. Abruña* \\ Department of Chemistry and Chemical Biology, Baker Laboratory, Cornell University, \\ Ithaca, New York 14853-1301
}

Received: February 14, 2001

\begin{abstract}
The interfacial reaction of terpyridyl-pendant poly-amido amine (PAMAM) dendrimers (dend- $n$-tpy; $n=4$, 8,32 ) and of bis-terpyridine containing bridging ligands (tpy-bridge-tpy), dissolved in $\mathrm{CH}_{2} \mathrm{Cl}_{2}$, with aqueous $\mathrm{Fe}^{2+}$ or $\mathrm{Co}^{2+}$ gives rise to film formation on HOPG and $\mathrm{Pt}(111)$ single crystal surfaces. Molecularly resolved STM images reveal that these films form highly ordered 2-D trigonal arrays, which appear to be composed of one-dimensional polymeric strands with a repeat unit of (tpy-dendrimer-tpy-M) $)_{x}$, in the case of dendrimers, or (tpy-bridge-tpy-M $)_{x}$, in the case of the bridging ligands. An extensive study with ligands of tailored architecture has been carried out, providing insight on the relationship between the ligand's molecular structure and that of the resulting films. The formation of ordered domains appears to be controlled, at least in part, by the rigidity of the molecule containing the terpyridine groups. Films derived from bridging ligands containing long chains did not give rise to observable periodic structures, whereas, rotationally hindered bridging ligands gave rise to well-ordered films. The use of optically active ligands gave rise to helical structures whose sense was dependent on the chirality of the molecule employed. The physical extension of the ordered domains appears to be delimited by terrace width on the HOPG surface. The dimensions obtained from an analysis of STM images are consistent with the estimated size (from molecular modeling) of the molecules from which the films were derived. In all cases, the films are electrochemically active and exhibit a metal based reversible wave at a formal potential that corresponds to that for the respective $\left[\mathrm{M}(\mathrm{tpy})_{2}\right]^{+2}$ complex.
\end{abstract}

\section{Introduction}

There is continuing interest in the preparation of surface structures of deliberate architecture with particular emphasis on systems capable of self-assembly. ${ }^{1,2}$ This effort has been driven by the many promising opportunities that such systems provide. The binding of transition metals to deliberately designed ligands provides an excellent platform for the preparation of such structures because both the strength and the kinetics of binding can be controlled. ${ }^{3}$ Moreover, the possibility of controlling surface structure at the molecular level by tailoring the synthesis of the component parts of the assembly could find applications in numerous fields. With this in mind, a great deal of effort has been placed on generating films from dendrimers and other supramolecular species.

Dendrimers, in particular, appear as very attractive surface modifiers because their size, geometry, and functionality can be exquisitely controlled. ${ }^{4-9}$ The modification of electrode surfaces with redox-active dendrimers could provide valuable insights not only for understanding interfacial redox reactions, but also in applications where they could be employed as electron-transfer mediators, ${ }^{10,11}$ catalysts, ${ }^{12-15}$ sensors, ${ }^{16,17}$ electrochromic, ${ }^{18,19}$ and electronic devices. ${ }^{20-22}$ Moreover, the possibility of controlling the surface structure of layers of dendrimers on electrode surfaces could open up novel opportunities in nanotechnology. ${ }^{23}$ Recent studies of dendrimers containing redox-active centers, based on transition metal complexes as well as organometallic species, point to their potential use as electrode surface modifiers. ${ }^{24-30}$ Similarly, there

† Part of the special issue "Royce W. Murray Festschrift". is also a continued interest in the use of bridging ligands for the preparation of materials of deliberately designed electrical, electrochemical and spectroscopic properties. ${ }^{31-35}$

Clearly, the ability to prepare well-ordered films of these species (dendrimers and bridges) as well as others could open new approaches for the generation of surfaces of deliberately designed architecture and functionality. Moreover, the ability to rely on a simple film-formation process would provide a convenient way to prepare a wide variety of films and explore broad systematic variations. $^{2}$

The deliberate control of surface structure requires a detailed understanding of adsorbate/adsorbate and adsorbate/substrate interactions, as well as knowledge of the structure, of the materials themselves or of related species, in the solid state. ${ }^{36,37}$ However, most experimental approaches have not been able to provide direct visualization, at the molecular level, of the structure of macromolecular layers adsorbed/assembled on surfaces. The ability to obtain molecularly resolved images of dendrimers on surfaces could provide a great deal of insight into how these surface assembly processes occur at the microscopic level and on the nature and strength of the interactions.

Scanning Probe Microscopy (SPM) techniques have been used for the study of the structure of adsorbed films with molecular resolution. ${ }^{38}$ However, most SPM studies of dendrimer films have been confronted by two principal challenges: (a) the interactions between the tip and the adsorbate disrupting the adsorbate layer, and (b) the effects of the tip's geometry when scanning features of size comparable to the tip's dimensions (this is commonly referred to as "convolution" or 


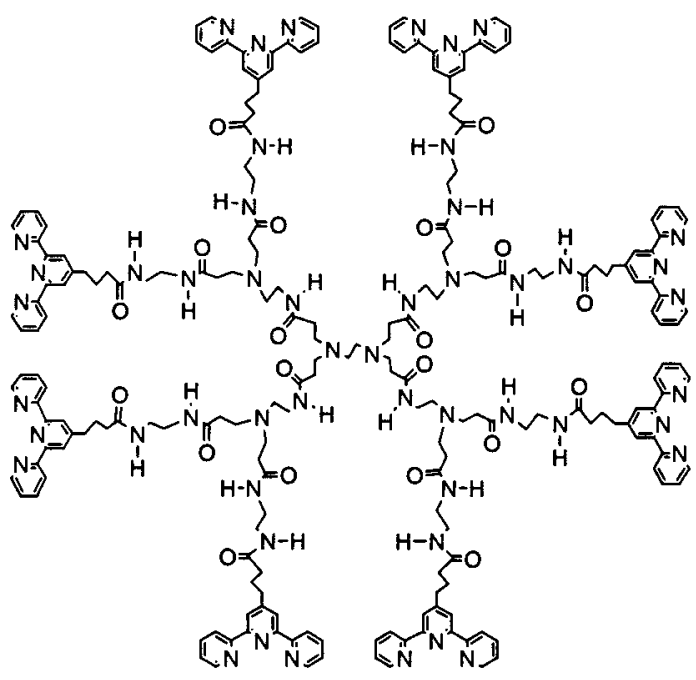

a) dend-8-tpy<smiles>c1ccc(-c2cc(CCc3ccc(CCc4cc(-c5ccccn5)nc(-c5ccccn5)c4)cc3)cc(-c3ccccn3)n2)nc1</smiles>

b) TEPET

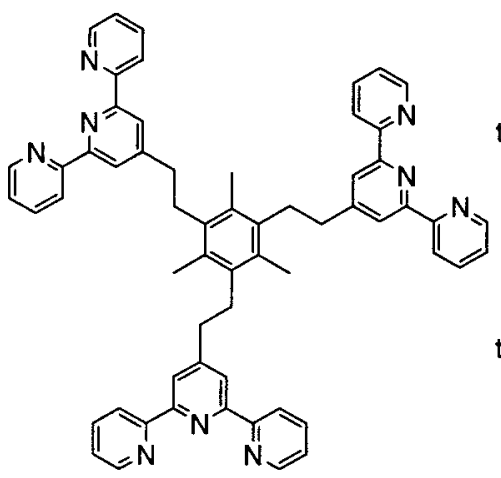

c) BTETET

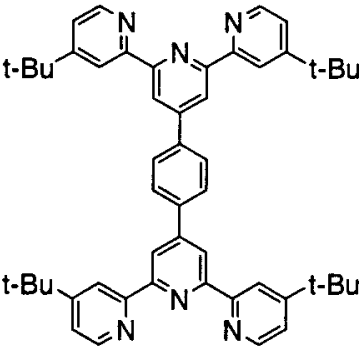

d) BBDTB
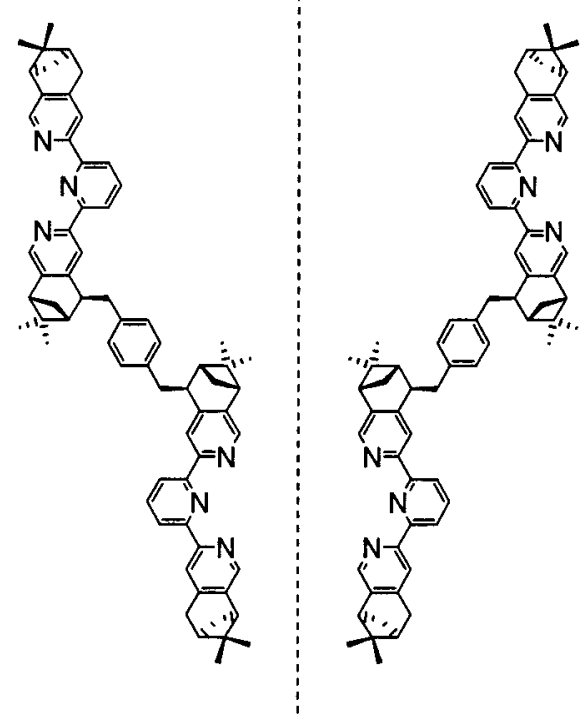

e) (-)-CTXCT f) (+)-CTXCT

Figure 1. Molecular structures of the different terpyridine containing ligands used (a) dend-8-tpy (b) TEPET (c) BTETET (d) BBDTB (e) (-)CTXCT (f) (+)-CTXCT.

"dilation" and is more evident in atomic force microscopy, AFM). ${ }^{39-41}$ The utility of SPM techniques (such as AFM or STM) for the direct visualization of dendrimers will likely be limited by the resolution of the scanning probe and the stability of the film.

We have prepared terpyridine-containing dendrimers and bridging ligands. As a ligand, terpyridine is well known to have very high affinity and facile kinetics for complex formation with transition metal ions such as $\mathrm{Fe}^{2+}$ and $\mathrm{Co}^{2+} .{ }^{42}$ By carrying out such metal complex formation reactions at the interface between two immiscible liquids containing the ligand and the metal ion, respectively, we have been able to prepare exceptionally well ordered arrays of metal complexes via metal-initiated selfassembly. Molecularly resolved STM images of these arrays have been obtained with the measured dimensions of the individual dendrimer units being very consistent with those obtained from simulations. ${ }^{43,44}$ Our ability to create very stable films through metal complexation and the ability to use STM for the imaging allow for very high-resolution imaging of such films. This approach may allow for the preparation on novel nanostructures of controlled composition and dimensionality and with electro and photochemical activity.

\section{Experimental Section}

a. Synthesis. 1. Dend-n-tpy. Dend- $n$-tpy (where $n=4,8$, $16,32,64)$ were prepared as described previously ${ }^{43,44}$ through the peptide coupling of a carboxylic acid-pendant terpyridine ligand with the appropriate poly-amido amine (PAMAM) starburst dendrimer. The structure of dend-8-tpy is presented in Figure 1a. The synthetic procedures leading to the bis $2,2^{\prime}: 6^{\prime}, 2^{\prime \prime}$-terpyridine based bridging ligands TEPET, BTETET, and BBDTB (Figure 1b,1c, and 1d, respectively) are described below. The synthesis of the chiral ligands (-)-CTXCT and (+)CTXCT (Figures 1e,1f) was accomplished through a 2-fold alkylation reaction starting from a chiral terpyridine precursor and $\alpha, \alpha^{\prime}$-dibromo- $p$-xylene. ${ }^{45}$

2. $4^{\prime}-\left(2-\left\{4-\left[2-\left(2,2^{\prime}: 6^{\prime}, 2^{\prime \prime}-\right.\right.\right.\right.$ Terpyridine $\left.-4^{\prime}-y l\right)$ ethyl $\left.] p h e n y l\right\}-$ ethyl)-2,2':6', $2^{\prime \prime}$-terpyridine (TEPET). A solution of $4^{\prime}$-methyl terpyridine $^{46}(0.74 \mathrm{~g}, 3 \mathrm{mmol})$ in $50 \mathrm{~mL}$ of dry tetrahydrofuran was cooled to $-40{ }^{\circ} \mathrm{C}$, and a solution of lithium diisopropyl 
amide $(1.7 \mathrm{~mL}, 2 \mathrm{M}, 3.4 \mathrm{mmol})$ was added through a syringe under nitrogen. The deep blue solution was allowed to warm to $-5^{\circ} \mathrm{C}$ and kept at this temperature for $1 \mathrm{~h}$. After cooling to $-20^{\circ} \mathrm{C}, \alpha, \alpha^{\prime}$-dibromo- $p$-xylene $(0.31 \mathrm{~g}, 1.2 \mathrm{mmol})$ was added to the reaction mixture, which was then left to warm to room temperature. After $15 \mathrm{~h}$, the blue mixture was quenched with ammonium chloride solution $(100 \mathrm{~mL}, 5 \%)$, and extracted with dichloromethane $(3 \times 200 \mathrm{~mL})$. The combined organic layers were washed with water $(100 \mathrm{~mL})$ and dried with $\mathrm{MgSO}_{4}$, and the solvent was removed under reduced pressure. To separate the 4 '-methyl terpyridine from the product, the residue, a yellow powder, was dissolved in $20 \mathrm{~mL}$ of dichloromethane, and 20 $\mathrm{mL}$ of hexane were added. Slow evaporation of the dichloromethane at $4{ }^{\circ} \mathrm{C}$ lead to the crystallization of a white solid, which was separated by filtration. Repetition of this crystallization procedure lead to a white powder. Yield: $0.25 \mathrm{~g}(0.41$ mmol, 34\%). ${ }^{1} \mathrm{H} \mathrm{NMR}\left(200 \mathrm{MHz}, \mathrm{CDCl}_{3}\right): 8.74(4 \mathrm{H}, \mathrm{d}, 4.5 \mathrm{~Hz})$, $8.63(4 \mathrm{H}, \mathrm{d}, 7.5 \mathrm{~Hz}), 8.36(4 \mathrm{H}, \mathrm{s}), 7.83(4 \mathrm{H}, \mathrm{dd}, 7.5 \mathrm{~Hz}, 7.5$ $\mathrm{Hz}), 7.83$ (4H, dd, $7.5 \mathrm{~Hz}, 4.5 \mathrm{~Hz}), 7.21$ (4H, s), 3.07 (8H, bs) HR-MS (ESI) Calculated for $\mathrm{C}_{40} \mathrm{H}_{33} \mathrm{~N}_{6}\left(\left[\mathrm{M}+\mathrm{H}^{+}\right]\right): 597.2767$ Found: 597.2758.

3. 4-(2-\{3,5-bis[2-(2,2':6', $2^{\prime \prime}-$ Terpyridine-4'-yl)ethyl]-2,4,6trimethylphenyl\}ethyl)- 2,2':6',2"-terpyridine (BTETET). A solution of $4^{\prime}$-methyl terpyridine $(0.62 \mathrm{~g}, 2.5 \mathrm{mmol})$ in $50 \mathrm{~mL}$ of dry tetrahydrofuran was cooled to $-30{ }^{\circ} \mathrm{C}$ (acetone/dry ice bath) under nitrogen and a solution of lithium diisopropylamide (1.4 $\mathrm{mL}, 2 \mathrm{M}, 2.8 \mathrm{mmol}$ ) was added through a syringe. The dark blue reaction mixture was warmed to $0{ }^{\circ} \mathrm{C}$ over a period of 1 $\mathrm{h}$ and subsequently cooled to $-20^{\circ} \mathrm{C}$. 2,4,6-tris(bromomethyl)mesitylene $(0.30 \mathrm{~g}, 0.75 \mathrm{mmol})$ was added, and the mixture was left to warm to room temperature. After $12 \mathrm{~h}$, the reaction mixture was quenched with $200 \mathrm{~mL}$ of $5 \% \mathrm{NH}_{4} \mathrm{Cl}$ solution, and the mixture was extracted with $3 \times 250 \mathrm{~mL} \mathrm{CH}_{2} \mathrm{Cl}_{2}$. The combined organic layers were washed twice with 200-mL portions of water. After drying the organic layers with $\mathrm{MgSO}_{4}$ the solvent was evaporated until a white solid started precipitating (approximately $20 \mathrm{~mL}$ ). The solid was removed through filtration, washed with $\mathrm{CH}_{2} \mathrm{Cl}_{2}$ and dried under vacuum $0.13 \mathrm{~g}$ (0.15 mmol, 20\%). $\left.{ }^{1} \mathrm{H} \mathrm{NMR} \mathrm{(200} \mathrm{MHz,} \mathrm{CDCl}_{3}\right): 8.75(6 \mathrm{H}, \mathrm{d}$, $4.7 \mathrm{~Hz}), 8.66(6 \mathrm{H}, \mathrm{d}, 6.9 \mathrm{~Hz}), 8.41(4 \mathrm{H}, \mathrm{s}), 7.83(6 \mathrm{H}, \mathrm{dd}, 7.6$ $\mathrm{Hz}, 7.5 \mathrm{~Hz}), 7.83(6 \mathrm{H}, \mathrm{dd}, 7.4 \mathrm{~Hz}, 4.9 \mathrm{~Hz}), 3.1\left(12 \mathrm{H}, \mathrm{A}_{2} \mathrm{~B}_{2}\right)$, $2.55(9 \mathrm{H}, \mathrm{s})$. HR-MS (ESI) Calcd for $\mathrm{C}_{60} \mathrm{H}_{53} \mathrm{~N}_{6}\left(\left[\mathrm{M}+\mathrm{H}^{+}\right]\right)$: 899.4424. Found: 899.4456.

4. 1,4-bis[4,4"-bis(1,1-Dimethylethyl)-2,2':6',2"-terpyridine$4^{\prime}$-yl]benzene (BBDTB). $\mathrm{NaOH}(1 \mathrm{~mL}, 1 \mathrm{M})$ was added to a benzene-1,4-dicarbaldehyde $(0.89 \mathrm{~g}, 6.7 \mathrm{mmol})$ and 2-acetyl4-tert-butylpyridine $\mathrm{e}^{47,48}(5 \mathrm{~g}, 28.2 \mathrm{mmol})$ solution in $100 \mathrm{~mL}$ of warm ethanol. The color of the solution changed immediately to red-brown, and a yellow precipitate began to form. The suspension was left stirring for 7 days, during which time the yellow precipitate redissolved. The dark brown solution was added to an aqueous $\mathrm{NH}_{4} \mathrm{Cl}$ solution $(200 \mathrm{~mL}, 5 \%)$, and the resulting suspension extracted with diethyl ether $(3 \times 150 \mathrm{~mL})$. The combined organic extracts were washed with water (100 $\mathrm{mL})$, dried $\left(\mathrm{MgSO}_{4}\right)$ and concentrated. The resulting light brown solid (5.5 g) was dissolved in methanol $(250 \mathrm{~mL})$, and ammonium acetate $(25 \mathrm{~g})$ was added. The solution was refluxed for $20 \mathrm{~h}$, and the formed precipitate collected and rinsed with methanol. The residue was dissolved in $50 \mathrm{~mL}$ of $\mathrm{CH}_{2} \mathrm{Cl}_{2}$ and filtered through a plug of aluminum oxide (neutral). The aluminum oxide was rinsed with $300 \mathrm{~mL}$ of $\mathrm{CH}_{2} \mathrm{Cl}_{2}$, and the solvent was removed to yield a white powder $0.22 \mathrm{~g}(0.14 \mathrm{mmol}$, $4 \%$ Yield). ${ }^{1} \mathrm{H}$ NMR (200 MHz, $\left.\mathrm{CDCl}_{3}\right): 8.82(4 \mathrm{H}, \mathrm{d}, 1.5 \mathrm{~Hz})$; $8.80(4 \mathrm{H}, \mathrm{s}) ; 8.68$ (4H, d, $5.2 \mathrm{~Hz}) ; 8.08$ (4H, s); 7.39 (4H, dd,
5.2, $1.9 \mathrm{~Hz}) 1.48(36 \mathrm{H}, \mathrm{s})$. HR-MS (ESI) Calcd for $\mathrm{C}_{52} \mathrm{H}_{57} \mathrm{~N}_{6}$ $\left(\left[\mathrm{M}+\mathrm{H}^{+}\right]\right): 765.4644$. Found: 765.4610.

b. Materials. $\mathrm{CH}_{2} \mathrm{Cl}_{2}$ (Fisher Scientific) was used as received. High Purity $\mathrm{FeSO}_{4} \bullet 7 \mathrm{H}_{2} \mathrm{O}$ (Aldrich) and high purity $\mathrm{CoSO}_{4} \bullet 6 \mathrm{H}_{2} \mathrm{O}$ (Aldrich) were used as received. Aqueous solutions were prepared using Millipore water of at least $18 \mathrm{M} \Omega$ resistance. HOPG substrates (Union Carbide ZYA grade or Structure Probe SPI-1 grade) of $1 \mathrm{~cm}^{2}$ were cleaved just prior to film preparation. $\mathrm{Pt}(111)$ electrodes were prepared according to Clavilier's method. ${ }^{49}$ Prior to use, the electrodes were flame annealed for $30 \mathrm{~s}$ and quenched in Millipore water.

c. Film Preparation and Characterization. For STM imaging, films of dendrimers and of bridging ligands were prepared by bringing into contact a $0.02 \mathrm{mM}$ solution of the dendrimer or bridging ligand in $\mathrm{CH}_{2} \mathrm{Cl}_{2}$ with an aqueous solution of $\mathrm{FeSO}_{4}$ or $\mathrm{CoSO}_{4}(0.1 \mathrm{M})$ on the surface of a freshly cleaved HOPG substrate. The reaction was allowed to proceed at room temperature for $24 \mathrm{~h}$. The surface was then thoroughly rinsed with $\mathrm{H}_{2} \mathrm{O}$ and $\mathrm{CH}_{2} \mathrm{Cl}_{2}$ to remove excess reactants. The samples were then mounted on the STM for analysis. This method of film preparation will be denoted as Method A in the text.

For electrochemical experiments, films were prepared by placing a freshly cleaved HOPG substrate or Pt(111) single crystal (of $0.05 \mathrm{~cm}^{2}$ area) electrode in a $\mathrm{CH}_{2} \mathrm{Cl}_{2}$ solution of the dendrimer or bridging ligand for $30 \mathrm{~min}$ and after rinsing with $\mathrm{CH}_{2} \mathrm{Cl}_{2}$ placed in aqueous $\mathrm{FeSO}_{4}$ or $\mathrm{CoSO}_{4}(0.1 \mathrm{M})$ for $15 \mathrm{~min}$. The substrate (HOPG or Pt(111)) was thoroughly rinsed with water. This procedure of film preparation will be referred to as Method B.

Ordered domains were observed in STM images for films derived from both methods and on both substrates. Because of the well-known and documented difficulties of obtaining molecularly resolved images of adsorbates on $\operatorname{Pt}(111)$, most STM imaging was done on HOPG. In general, surface coverages were more reproducible and easier to control when employing Method B. Method A, involving the interfacial reaction of two solutions, generally yielded a higher density of 3-D clusters over larger areas of the surface. This was especially the case for the higher generation dendrimers, and it was difficult, if not impossible, to have control over surface coverage. On the other hand, Method A represents a very simple procedure for the preparation of films that can be imaged through STM. Surfaces of films prepared through both methods were mostly covered by monolayer equivalents of the film, although in both cases the presence of 3-D aggregates was evident.

Cyclic voltammetry of the modified electrodes was carried out in acetonitrile/0.1 M TBAP (tetra- $n$-butylammonium perchlorate)(G. F. S. Chemicals). Acetonitrile (AN) (UV Grade, Burdick \& Jackson) was dried over $4 \AA$ molecular sieves for $72 \mathrm{~h}$ prior to use. TBAP was recrystallized three times from ethyl acetate (Fisher Scientific) and dried under vacuum for 72 h. All other chemicals were of at least reagent grade quality and were used as received. Cyclic voltammetry was carried out on a BAS CV-27 potentiostat/galvanostat (Bioanalytical Systems) and recorded on a BAS $\mathrm{X}-\mathrm{Y}$ recorder (Bioanalytical Systems). The electrodes were placed in a two compartment cell using a three electrode configuration $(\mathrm{Ag} / \mathrm{AgCl}$ or SSCE, (sodium saturated calomel electrode) as the reference electrode, and a large area Pt wire coil as the counter electrode). Surface coverages were calculated by integrating the charge under the metal based oxidation wave at slow sweep rates (typically 25 $\mathrm{mV} / \mathrm{s}$ ). Experiments at different ionic strength were carried out on films of dend- $n$-tpy $/ \mathrm{M}^{2+}$ prepared by Method B by obtaining cyclic voltammetric data using different TBAP concentrations. 
TABLE 1: Sizes of the Iron(II) Coordinated Dendrimers Based on Molecular Modeling Compared to the Sizes Obtained from STM Imaging

\begin{tabular}{|c|c|c|}
\hline \multirow[b]{2}{*}{ dendrimer generation } & \multicolumn{2}{|c|}{ diameter of the dendrimer $(\mathrm{nm})$} \\
\hline & STM experiments & molecular modeling \\
\hline dend-4-tpy $/ \mathrm{Fe}^{2+}$ & 2.7 & 2.67 \\
\hline dend-8-tpy/Fe ${ }^{2+}$ & 4.5 & 4.28 \\
\hline dend-16-tpy/Fe ${ }^{2+}$ & 7.3 & $7.0^{a}$ \\
\hline dend-32-tpy/Fe ${ }^{2+}$ & 9.0 & $b$ \\
\hline
\end{tabular}

${ }^{a}$ Obtained from CaCHE calculations on dend-16-tpy $/ \mathrm{Ru}^{2+} \cdot{ }^{b} \mathrm{Com}-$ puter resource limitations precluded us from carrying out these calculations

Double Potential Step Chrono-Amperometry (DPSCA) was carried out on a Princeton Applied Research PAR-283 (EG \& $\mathrm{G}$ Instruments) potentiostat and data were recorded on a pentium class computer through a GPIB (National Instruments) interface. All potentials for DPSCA measurements were referenced to a $\mathrm{Ag} / \mathrm{AgCl}$ electrode. DPSCA experiments were carried out in AN/0.1 M TBAP. For DPSCA experiments films of dend-8tpy/Co $\mathrm{Co}^{2+}$ and of dend-8-tpy/Fe ${ }^{2+}$ were prepared by Method $\mathbf{B}$. For films of dend-8-tpy/Co ${ }^{2+}$, an initial potential of $0.00 \mathrm{~V}$ was applied for $2 \mathrm{~s}$, then stepped to $+0.50 \mathrm{~V}$ and held at this value for $2 \mathrm{~s}$ before stepping back to $0.00 \mathrm{~V}$. For films of of dend8 -tpy/ $/ \mathrm{Fe}^{2+}$, a similar program was employed except the applied potentials were $+0.80 \mathrm{~V},+1.40 \mathrm{~V}$ and $+0.80 \mathrm{~V}$, respectively. The values of the applied potentials were chosen to be well beyond those necessary for oxidation/rereduction of the metal centers within the film.

The sizes of the dendrimers and the bridging ligands were estimated by simple molecular mechanics calculations using HyperChem (HyperCube, LTD) and CaCHE (Oxford Molecular) software (see Table 1). Difficulties associated with the convergence of the calculations (due largely to size) precluded carrying out calculations on dend-32-tpy and larger dendrimers.

Scanning Tunneling Microscopy (STM) experiments were carried out in air, using a Digital Instruments Nanoscope E controller, and a Molecular Imaging $10 \mu \mathrm{m}$ scanner. The Molecular Imaging STM head was placed inside a Molecular Imaging PicoIC Isolation Chamber. 80:20 Pt:Ir (GoodFellow) tips were mechanically cut or electrochemically etched in a $\mathrm{CaCl}_{2} / \mathrm{HCl}$ aqueous solution following published procedures. ${ }^{50}$ The tips were tested by scanning over a freshly cleaved HOPG surface at atomic resolution prior to imaging the sample. Scanning was carried out at 512 samples resolution to ensure the highest resolution possible. All images shown are unfiltered, taken on-line and no off-line zoom was used. Bias voltages between +140 and $+200 \mathrm{mV}$ (positive bias on the sample so that electrons flow from the tip to the sample) and set point currents between 1.0 and $2.0 \mathrm{nA}$ were employed. The scan rates were between $4 \mathrm{~Hz}$ for the larger scale images and up to $15 \mathrm{~Hz}$ for the smaller size images.

\section{Results and Discussion}

a. Electrochemical Characterization of dend- $\boldsymbol{n}$-tpy films. On HOPG, films were prepared following Method A for several dendrimer generations and different bridging ligands over a freshly cleaved HOPG substrate as described in the Experimental Section. Cyclic voltammograms of dend-8-tpy/ $\mathrm{Fe}^{2+}$ derived films exhibited a metal-based reversible redox couple with a formal potential $\left(E^{\circ \prime}\right)$ value of $+1.03 \mathrm{~V}$ vs SSCE which is very close to that reported for $\left[\mathrm{Fe}(\text { tpy })_{2}\right]^{2+}\left(E^{\circ \prime}=+1.10 \mathrm{~V}\right.$ vs SSCE) and unambiguously establishes the nature of the immobilized complex. ${ }^{51}$ A cyclic voltammogram for an HOPG
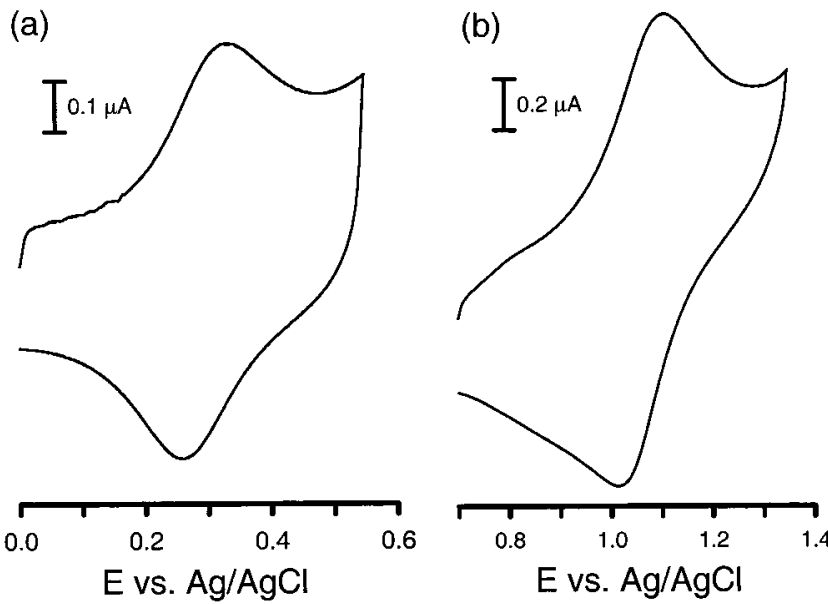

Figure 2. Cyclic voltammograms for films derived from the interfacial reaction of (a) dend-8-tpy/Co ${ }^{2+}$ (b) dend-8-tpy/ $/ \mathrm{Fe}^{2+}$. $\mathrm{Pt}(111)$ electrode of $0.05 \mathrm{~cm}^{2}$ area, in acetonitrile/0.1 M TBAP. Scan rate of $50 \mathrm{mV} / \mathrm{s}$. Films were prepared by Method B.

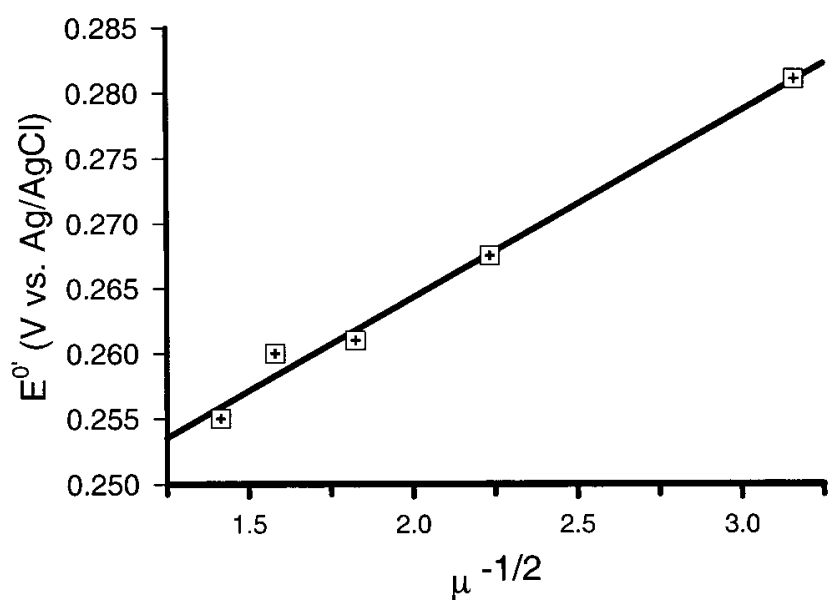

Figure 3. Plot of formal potential $\left(E^{\circ}\right)$ vs $1 /(\mu)^{1 / 2}(\mu=$ ionic strength) for films of dend-8-tpy/ $/ \mathrm{Co}^{2+}$

electrode modified with a film of dend-8-tpy/ $/ \mathrm{Fe}^{2+}$ is presented in Figure 5a. The surface coverage for such a modified electrode was considerably higher than that corresponding to a monolayer of adsorbed material due to the presence of 3-D aggregates. No other electrochemical analysis was carried out on films prepared by Method A (other than to establish the presence of the $\left[\mathrm{M}(\mathrm{tpy})_{2}\right]^{2+}$ complex $)$ due to the lack of control over the amount of film formed (coverages largely exceeding a monolayer for all different dendrimer generations and bridging ligands used). It is worth mentioning that films derived from all dendrimers and bridging ligands used exhibited similar cyclic voltammetric profiles (with only small variations in $E^{\circ \prime}$ for a given metal i.e., $\mathrm{Co}^{2+}$ or $\mathrm{Fe}^{2+}$ ), establishing the formation of the respective $\left[\mathrm{M}(\text { tpy })_{2}\right]^{2+}$ complexes.

A more careful electrochemical characterization was carried out on $\mathrm{Pt}(111)$ electrodes with films prepared by Method B. In the case of dend- $n$-tpy/ $\mathrm{Co}^{2+}$ derived films prepared by Method $\mathbf{B}$, the surface coverages were closer to those of a monolayer equivalent of the film (at least for films derived from dend-4tpy and dend-8-tpy and using sizes for the species obtained from molecular modeling) and considerably less than surface coverages of films prepared by Method A. Figure 2, parts a and b, shows cyclic voltammograms for films prepared by Method B and derived from dend-8-tpy/ $/ \mathrm{Co}^{2+}$ and dend-8-tpy/ $\mathrm{Fe}^{2+}$, respectively. For all the dendrimer generations, surface coverages were higher than a monolayer equivalent due to the formation 


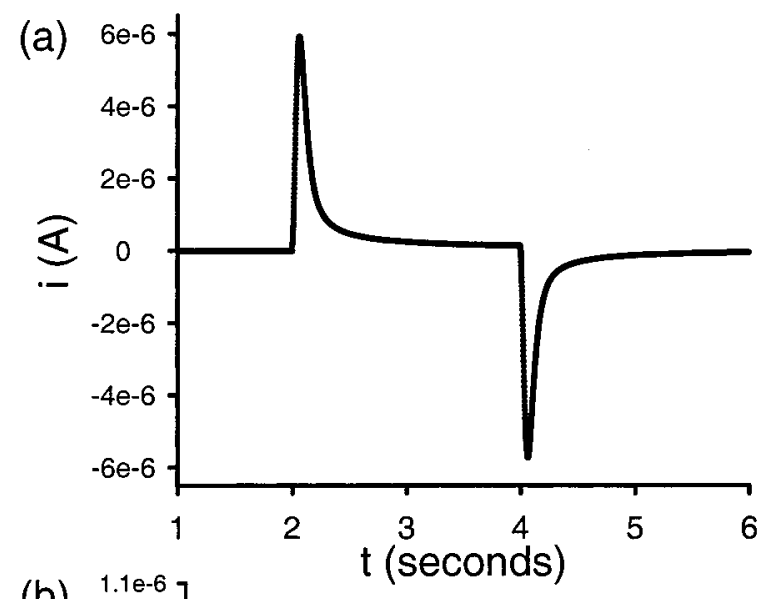

(b)

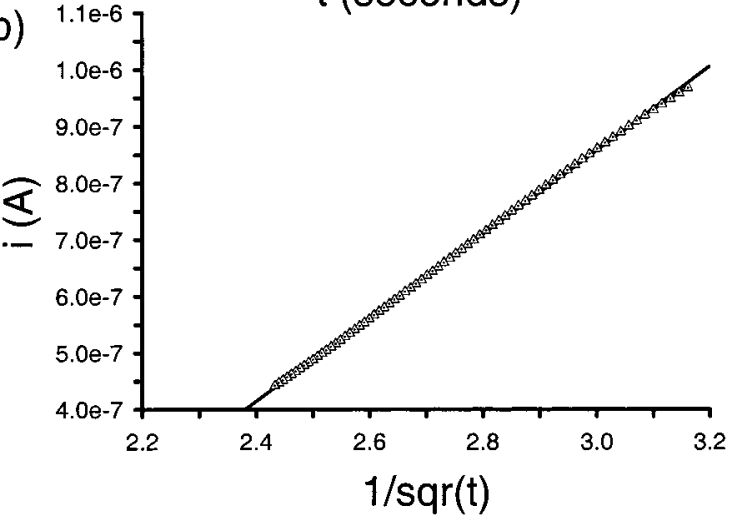

Figure 4. DPSCA experiments of dend-8-tpy/Co ${ }^{2+}$ films (a) Current/ time transient (b) Plot of i vs $t^{-1 / 2}$ used to obtain $\mathrm{D}_{\mathrm{o}}$ for dend-8-tpy/ $\mathrm{Co}^{2+}$.

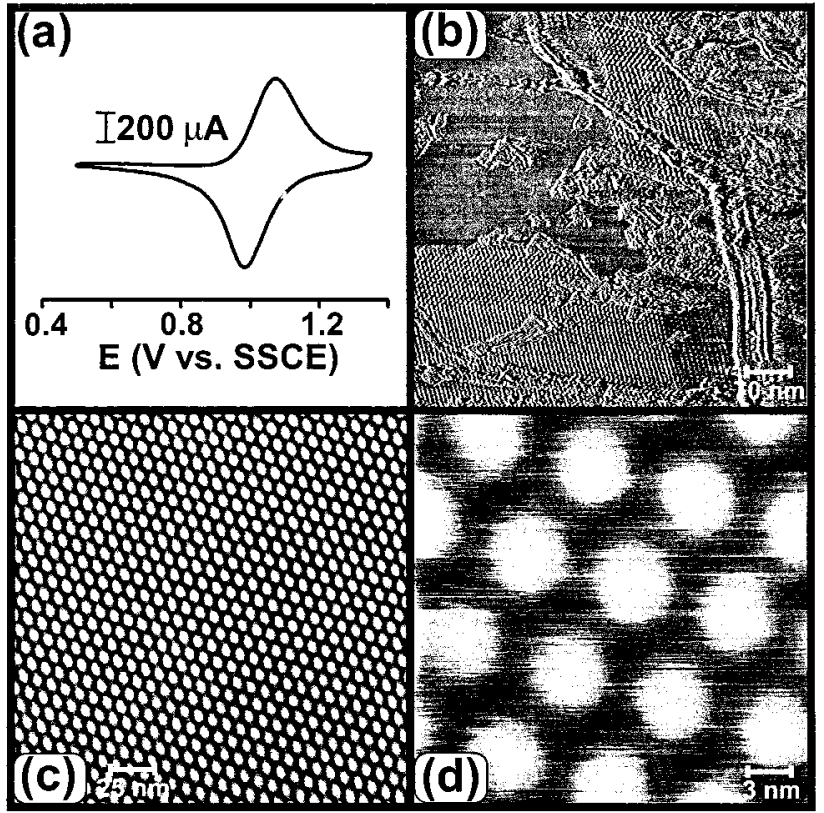

Figure 5. (a) Cyclic voltammogram of a dend-8-tpy/Fe ${ }^{2+}$ film on an HOPG electrode (b) $550 \times 550 \mathrm{~nm}$ STM image of dend-8-tpy/ $/ \mathrm{Fe}^{2+}$ film (c) $200 \times 200 \mathrm{~nm}$ close up of an ordered region (d) $26 \times 26 \mathrm{~nm}$ close-up of the same area.

of 3-D aggregates. In all cases, the formal potentials, $E^{\circ \prime}$, of the cyclic voltammetric waves associated with the metal-based oxidation were consistent with the formation of the corresponding $\left[\mathrm{M}(\mathrm{tpy})_{2}\right]^{2+}$ complex. A more careful analysis of the electrochemical responses showed that films derived from dend-4-tpy and dend-8-tpy had surface coverages that were closer to a monolayer equivalent, whereas films derived from dend-16-tpy
TABLE 2: Electrochemical Characterization of $\mathrm{Co}^{2+} /$ Dend- $n$-tpy Films. Pt(111) Electrode, $A=0.15 \mathrm{~cm}^{2}$. Sizes for Dendrimers Were Obtained from Molecular Modeling

\begin{tabular}{|c|c|c|c|c|c|}
\hline $\begin{array}{l}\text { dendrimer } \\
\text { generation }\end{array}$ & $\begin{array}{l}E^{\circ \prime} \\
(\mathrm{V})\end{array}$ & $\Delta E_{\mathrm{p}}(\mathrm{mV})$ & $\begin{array}{c}\Delta E_{\text {fwhm }} \\
(\mathrm{mV})\end{array}$ & $\begin{array}{c}\text { charge } \\
\left(10^{-7} \mathrm{C}\right)\end{array}$ & $\begin{array}{c}\text { coverage } \\
\text { (monolayer } \\
\text { equivalents) }\end{array}$ \\
\hline dend-4-tpy/Co ${ }^{2+}$ & +0.278 & 90 & 98 & 14 & 2.5 \\
\hline dend-8-tpy/Co ${ }^{2+}$ & +0.273 & 45 & 98 & 7.5 & 3.7 \\
\hline dend-16-tpy/Co ${ }^{2+}$ & +0.263 & 65 & 150 & 11 & 14 \\
\hline dend-32-tpy/Co ${ }^{2+}$ & +0.255 & 70 & 114 & 87 & $16^{a}$ \\
\hline
\end{tabular}

${ }^{a}$ Size obtained from STM images.

and dend-32-tpy, had coverages that were well above a monolayer. Table 2 presents a more detailed electrochemical characterization of the dendrimer films, showing the surface coverages obtained from cyclic voltammetry for the dend- $n$ tpy/ $\mathrm{Co}^{2+}$ films. This behavior can be explained as the larger dendrimers (dend-16-tpy and dend-32-tpy) having a higher tendency to form 3-D aggregates, likely as a result of the much larger number of terpyridyl groups oriented towards the interface. This is evidenced in Table 2 as a rather sharp increase in the surface coverage (number of complexed metal centers) when the dendrimer generation changes from dend-8-tpy to dend-16-tpy again suggesting the formation of 3-D aggregates.

It was also observed that the formal potentials for the films as well as the shape of the voltammetric waves varied with the different dendrimer generations. The formal potential for the $\mathrm{Co}^{2+} / \mathrm{Co}^{3+}$ process shifted in the negative direction as the dendrimer generation increased. This can be attributed to a better stabilization of the $\mathrm{Co}^{3+}$. Assuming that the films consist of 1-D chains, there would be, on average, one metal center per dendrimer molecule so that the larger sized dendrimers would allow for a more stable charge distribution due, at least in part, to a lower charge density. The full width at half-maximum $\left(\Delta E_{\mathrm{FWHM}}\right)$ increased as the dendrimer generation, from which the films were derived, increased. In particular, note the significant increase for films derived from dend-8-tpy and dend16-tpy. The increase in the $\Delta E_{\mathrm{FWHM}}$ (which deviates from the value of $90.6 \mathrm{mV}$ for the case of no interactions between adsorbates) suggests that as 3-D aggregates tend to form, there are more electrostatic repulsions among the charges. This result is consistent with the other electrochemical data for these dendrimer films. It is also worth mentioning that in all cases, there was a singular wave for the metal based redox process indicating that there are no ligand mediated metal metal interactions. This was independent of whether a particular ligand (or dendrimer) gave rise to ordered film formation.

Further characterization was carried out by determining the effects of ionic strength on the voltammetric response as well as carrying out DPSCA measurements to determine the value of the apparent diffusion coefficient. These studies are important as they will provide a great deal of insight into electrostatic charge screening on one hand, and charge propagation dynamics on the other. In terms of the ionic strength dependence studies, it was found that the formal potential, $E^{\circ \prime}$, for films derived from dend-8-tpy/ $\mathrm{Co}^{2+}$ decreased (small but noticeable change) with increasing ionic strength (Figure 3). A similar behavior was also observed for films derived from dend-8-tpy/ $\mathrm{Fe}^{2+}$. These observations suggest that at higher ionic strength there is an overall stabilization of the oxidized species $\left(\mathrm{Co}^{3+}\right.$ or $\left.\mathrm{Fe}^{3+}\right)$, likely due to a better screening of the charges and easier charge compensation by counterions.

DPSCA was carried out in order to gain a better understanding of charge propagation dynamics. Such studies were carried out for films derived from dend-8-tpy/ $\mathrm{Co}^{2+}$ and dend-8-tpy/ $\mathrm{Fe}^{2+}$ 
and results for the former are presented in Figure 4. It is well established that for redox active films charge propagation can be described as a diffusional process characterized by an apparent diffusion coefficient. ${ }^{52}$ The apparent diffusion coefficient can be obtained from potential step experiments and the use of the Cottrell equation (see eq 1),

$$
i=\frac{n F A C_{0} D_{0}^{1 / 2}}{\pi^{1 / 2} t^{1 / 2}}
$$

where $i$ is the current, $n$ is the number of electrons transferred, $F$ is the Faraday's constant, $A$ is the surface area of the electrode, $D_{0}$ is the diffusion coefficient, and $C_{0} *$ is the bulk concentration. A plot of $i$ vs $1 /(t)^{1 / 2}$ will be linear at short times and from the slope the apparent diffusion coefficient can be derived.

From such an analysis, the apparent diffusion coefficient for films derived from dend-8-tpy $/ \mathrm{Co}^{2+}$ and dend-8-tpy/ $\mathrm{Fe}^{2+}$ were determined to be $1.3 \pm 0.2 \times 10^{-8} \mathrm{~cm}^{2} / \mathrm{s}$ and $5 \pm 2 \times 10^{-7}$ $\mathrm{cm}^{2} / \mathrm{s}$, respectively. These results show that the electron-transfer rate for $\mathrm{Fe}^{2+} / \mathrm{Fe}^{3+}$ is over 1 order of magnitude faster than that of $\mathrm{Co}^{2+} / \mathrm{Co}^{3+}$. Such a difference would be the anticipated result for systems with widely different self-exchange rates, as is the case in the present context. The contribution of self-exchange to apparent diffusion coefficient measurements is well documented and is generally expressed through the Dahms-Ruff equation (eq 2), where the apparent diffusion coefficient, $D_{\text {app, }}$ consists of contributions form physical motion $\left(D_{0)}\right.$ and selfexchange $\left(k_{\mathrm{ex}}\right)$,

$$
D_{\text {app }}=D_{0}+\frac{\pi}{6} \delta^{2} C k_{\text {ex }}
$$

where $\delta$ represents the average jump distance for the reacting pair, and $C$ is the total concentration.

The electrochemical results also suggest that the films are structurally stable (the potential can be repeatedly swept without film degradation) and that they can screen charges quite effectively over a wide range of supporting electrolyte concentrations. These properties make them interesting candidates as electrode modifiers for a multitude of applications. The structural properties of these films is discussed in detail below.

b. Structure of Films Derived from Dendrimers. Dend-8tpy was chosen for initial studies because molecular modeling studies suggested that the number of ligands on its periphery (8) and their orientation made it a good candidate for film formation. After the complex formation reaction (see Experimental Section), the sample was allowed to dry in air. STM measurements showed a mixture of well-ordered domains and three-dimensional clusters; both spread over large areas of the HOPG substrate. Figure 5b shows a large area of such a film showing both the well ordered regions as well as the disordered, 3 -D aggregates. These well ordered regions are reminiscent of previously reported Moiré patterns for bare HOPG surfaces and resulting from a small-angle rotation (misorientation) between the top and the underlying layer(s) of the HOPG substrate..$^{53-61}$ This rotation creates an angle-dependent super-periodicity $\mathrm{P}(\mathrm{P}$ $=2.45 \AA / 2 \sin (\theta / 2)$; where $\theta$ is the angle between the hexagonal lattices) that is superimposed on the HOPG image. However, based on the properties of these Moiré patterns, particularly their bias dependency and variable periodicity, we can unambiguously rule them out as being responsible for the images reported here (see ref 62 and its supplemental information).

From inspection of the STM images, some 3-D clusters appear to form, particularly at step edges. ${ }^{62}$ Also observable

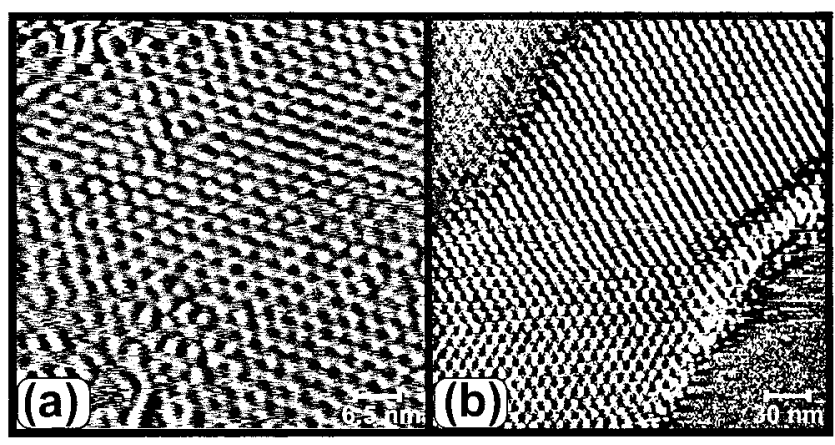

Figure 6. (a) Medium resolution STM image $(52 \times 52 \mathrm{~nm}$, unfiltered $)$ of dend-4-tpy/ $\mathrm{Fe}^{2+}$ on HOPG. (b) $243 \times 243 \mathrm{~nm}$ of dend-32-tpy/ $/ \mathrm{Fe}^{2+}$.

are extensive regions of the HOPG substrate covered by a wellordered film. Closer examination of the well-ordered regions showed a trigonal packing of the film. Figure $5 \mathrm{c}$ shows a closeup of part of the ordered regions apparent in Figure $5 \mathrm{~b}$ and illustrates the packing on the HOPG surface. Similar highly ordered arrays could be obtained by viewing virtually any of the ordered regions. The substrate structure appears to play a role in the formation of well-ordered films. Whereas larger substrate imperfections appear to be covered by 3-D clusters, STM images show that the size of the ordered domains is dependent on terrace width and delimited by the step edges on the substrate. We previously suggested that the highly ordered regions within the terraces are likely the result of 2-D packing of 1-D strands, ${ }^{62}$ where the repeat unit would ostensibly be (tpy-

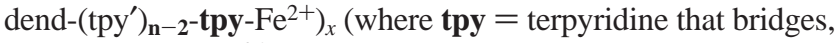
that is binds to $\mathrm{Fe}^{2+}$, and tpy' $=$ terpyridine not coordinated to an $\mathrm{Fe}^{2+}$ center). The question then arises as to why should such structures form at all given that the formation of $\left[\mathrm{Fe}(\mathrm{tpy})_{2}\right]^{2+}$ (and of $\left[\mathrm{Co}(\mathrm{tpy})_{2}\right]^{2+}$ ) is kinetically facile, the formation constant has a large value and there are 8 (and up to 64) terpyridine units per dendrimer molecule. As we have pointed to previously, we believe that a combination of factors might be responsible for this. First of all, it should be recalled that the reaction is taking place at the interface between two immiscible liquids and although the interface has a finite thickness, the reaction in 2 -dimensions is favored. It also seems that the orientation of the terpyridine groups favors the formation of 1-D chains and that the formation of a real 2-D array (rectangular array) is kinetically and/or sterically hindered in most dendrimers.

The quality and stability of the STM images were relatively insensitive to changes in imaging conditions, such as the tunneling bias (voltage) and current indicating that the films are very stable. This is in stark contrast to most, if not all, reports of images of dendrimers on surfaces. ${ }^{63}$ Simple calculations (using the modeling programs HYPERChem) suggest a feature size of $4.5 \mathrm{~nm}$ for dend-8-tpy, which is in excellent accordance with the dimensions derived from an analysis of the STM images.

In an effort to better understand the film formation of these dendrimers, we attempted to image films, prepared in the same fashion, of other terpyridine dendrimer generations. Figure $6 \mathrm{a}$ shows that highly ordered films can also be obtained for dend4-tpy/ $/ \mathrm{Fe}^{2+}$. Although, in this case, the images were not as sharply defined, they are qualitatively very similar. In addition, the size of the features is approximately $2.7 \mathrm{~nm}$ in diameter, which is consistent with the smaller size of dend-4-tpy relative to dend-8-tpy and is also consistent with results obtained from computer modeling.

Images were also obtained with dend-32-tpy containing 32 terpyridines on the periphery. Figure $6 \mathrm{~b}$ shows an STM image 
derived from dend-32-tpy/Fe ${ }^{2+}$. Although well ordered domains could be obtained, the films were not as well ordered as those derived from dend-8-tpy. The size of the features observed is considerably larger than the size of features of films derived from dend-4-tpy and dend-8-tpy consistent with its larger size. However, a more thorough size analysis could not be completed. Because of size limitations (number of atoms/degrees of freedom), we were precluded from carrying out calculations on this and larger dendrimers, as was already mentioned in the Experimental Section.

As observed from STM images, of all the dendrimers investigated, films derived from dend-8-tpy resulted in the largest (in terms of area of HOPG covered), better ordered domains. We believe that this is due, at least in part, to the fact that there are eight terpyridines, which apparently represents a good compromise in terms of size, stability, number of terpyridines (especially those pointing toward the interface) and geometry for the terpyridine groups to be able to bind to $\mathrm{Fe}^{2+}$ (and $\mathrm{Co}^{2+}$ ) centers and form highly ordered films. In the case of dend-4-tpy, the fact that it only has four terpyridine units would appear to give rise to strong steric constraints making film formation more difficult. The larger dendrimers (dend-16tpy and dend-32-tpy) exhibited a higher tendency to form 3-D structures, likely as a result of the larger number of terpyridyl groups oriented toward the interface. Both electrochemistry results and STM images suggest the tendency of the higher generation dendrimers to form 3-D aggregates. Both techniques also point toward the high structural stability of these films.

Although a number of factors, including the metal ion concentration, the solubility of the dendrimer and metal ion in the different phases and in the interfacial region, and the structure of the substrate, appear to be important in controlling the structure of the resulting films, it seems that the most important (and ostensibly governing) factor for the formation of well-ordered films is the geometric disposition and rotational constraints of the terpyridyl groups within the dendrimer unit.

c. Films Derived from bis-Terpyridyl Bridging Ligands. Given that in the formation of the above-mentioned ordered arrays only two of the terpyridine ligands are ostensibly bound to a metal center, and that the geometric disposition of the ligand groups appears to be the most important factor in the formation of well-ordered films, it should be possible to prepare ordered structures with ligands that have two (or more) terpyridine units separated by a bridge. With this in mind, we have synthesized several bridging ligands (presented in Figure 1) and which are, for simplification, referred to as TEPET, BTETET and BBDTB, that might allow for the preparation of novel surface structures.

As can be ascertained from Figure 1b, TEPET is a bridging ligand consisting of two terpyridine units connected through a bis 1,4 diethyl-phenyl bridge. Figure 7 shows an STM image of an HOPG electrode modified with a film derived from TEPET upon (interfacial) reaction with $\mathrm{Fe}^{2+}$. Contrary to the images presented previously, there does not appear to be any region of the surface that is well-ordered. The lack of ordering could be attributed to the rotational freedom of the bridge. In the case of the dendrimers, most of the terpyridine groups were rotationally hindered, which we believe facilitated film growth.

We were also interested in the preparation of films with different (from linear) topology. For this purpose, BTETET was synthesized. As shown in Figure 1c., BTETET has a trigonal disposition of the three pendant terpyridine groups although the brigding among them is structurally very similar to that of TEPET. Not surprisingly (at least in retrospect), the same limitations as for TEPET were encountered so that no ordered

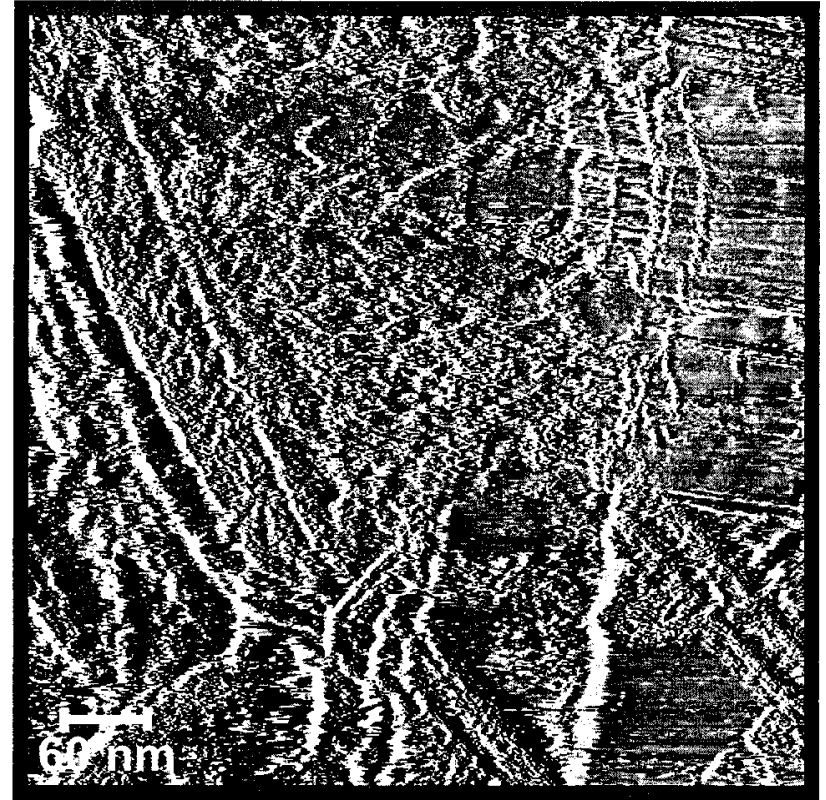

Figure 7. Low resolution $(550 \times 550 \mathrm{~nm}) \mathrm{STM}$ image of film derived from BTETET/Fe ${ }^{2+}$.

films were formed. Figure 7 shows the image for a film derived from BTETET where (similar to the case of TEPET) the lack of long-range order is evident. From the foregoing, it appears that the rotational freedom of both TEPET and BTETET will not allow the films to grow in an ordered fashion. In the case of BTETET, it might also be very difficult for the molecules to arrange in such a fashion that they can bind to three other ligands at the liquid-liquid interface forming a honeycomb structure. Because metal coordination to the tepyridine groups is rapid, this appeas to govern film formation giving rise to disordered films.

In an effort to overcome the limitations imposed by the rotational freedom present in the previous two cases, the bisterpyridine bridging ligand, BBDTB presented in Figure 1d, was synthesized. Following the same procedures as above, we were able to prepare highly ordered films of the $\mathrm{Fe}^{2+}$ complex and whose STM images are presented in Figure 8, parts a and b. Highly ordered arrays were obtained and the dimensions, obtained from an analysis of the images, were consistent with the size of the ligand obtained from computer simulations. The ability to prepare such ordered films when the rigidity of the bridging ligands is controlled, points to the requirements that are necessary and whcich can be achieved by suitable modification of the ligand, and to the importance of the geometry of the ligand. From the foregoing, it appears that it is necessary to control the degree of rotational freedom of the ligands in order to form well-ordered films. The success in identifying the relationship between a ligand's structure and its ability to give rise to well-ordered films plus the ability of synthesizing molecules of desired and deliberate architecture has allowed for the testing of different molecular templates for the preparation of films as detailed above.

Although the emphasis has been on the formation of $\mathrm{Fe}^{2+}$ complexes, we have also prepared analogous films using $\mathrm{Co}^{2+}$ which, similar to $\mathrm{Fe}^{2+}$, has facile kinetics of complex formation and a large formation constant. Films derived from dend-4-tpy and the BBDTB ligand using $\mathrm{Co}^{2+}$ as the transition metal ion were prepared in the same fashion as described earlier for $\mathrm{Fe}^{2+}$. Figure 9, parts a and b, shows STM images of the $\mathrm{Co}^{2+}$ derived films of dend-4-tpy and the BBDTB ligand, respectively. From 


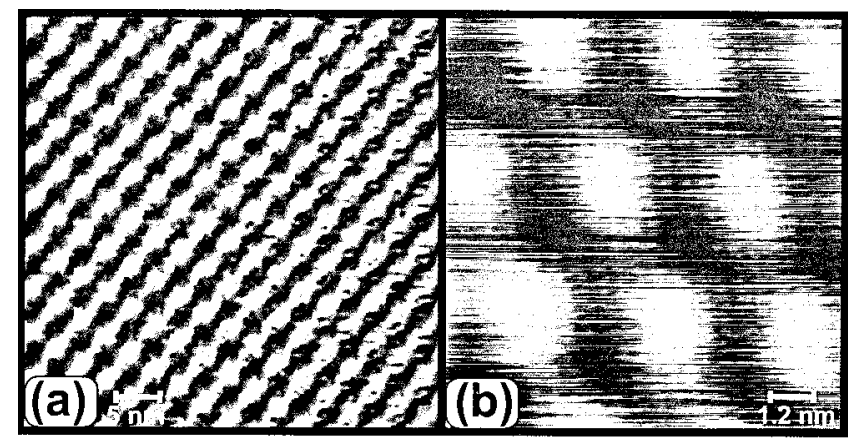

Figure 8. (a) Medium resolution STM image $(40 \times 40 \mathrm{~nm}$, unfiltered $)$ of film derived from BBDTB/ $\mathrm{Fe}^{2+}$ on HOPG. (b) High-resolution STM image $(9.3 \times 9.3 \mathrm{~nm})$ of the film presented in Figure $8 \mathrm{a}$.

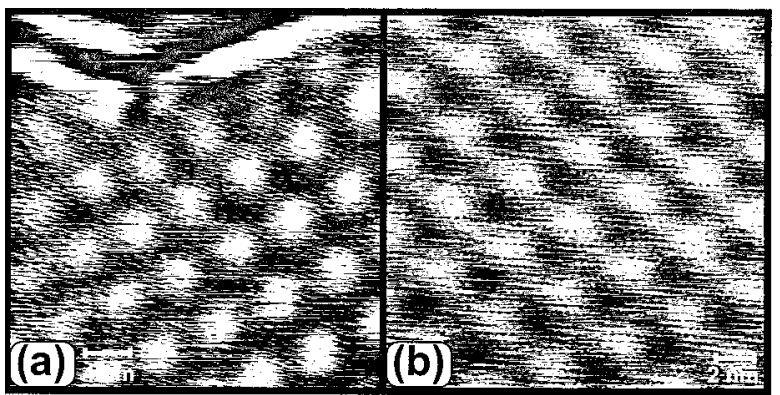

Figure 9. (a) Medium resolution STM image $(30 \times 30 \mathrm{~nm})$ of dend4 -tpy/Co $\mathrm{Co}^{2+}$ film. (b) Medium resolution STM image $(20 \times 20 \mathrm{~nm})$ of $\mathrm{BBDTB} / \mathrm{Co}^{2+}$ film.

these images, it is evident that very well-ordered films can also formed with $\mathrm{Co}^{2+}$ and that the films are very similar in nature and structure to those derived from $\mathrm{Fe}^{2+}$. A closer inspection, however, reveals that for the $\mathrm{Co}^{2+}$ derived films the features observed have slightly lower brightness, are somewhat smaller and more globular. Although somewhat speculative in our part, this might arise as a result of the oxidation of the $\mathrm{Co}^{2+}$ to $\mathrm{Co}^{3+}$ in air induced by the tip bias (recall that the samples were imaged in air) or to differences arising from tunneling through different metals. Similar contrast differences in metal complexes have been reported previously where the contrast of the features is dependent on the metal complexed and its oxidation state. ${ }^{64}$

d. Films Derived from Chiral Bridging Ligands. In an effort to explore further topological variations, we have synthesized terpyridine based bridging ligands that are chiral in nature (and enantiomerically pure) and which, for simplicity, we have termed $( \pm)$-CTXCT (shown in Figure 1e). A question that immediately arises is whether films derived from different enantiomers can be distinguished by STM. We have prepared films derived from both enantiomers with $\mathrm{Fe}^{2+}$ in the same fashion as previously described for the other ligands. Films prepared from the reaction of $(-)-\mathrm{CTXCT}$ with $\mathrm{Fe}^{2+}$ showed large, very well-ordered regions as shown in Figure 10a. These ordered domains are reminiscent in size and structure to films derived from BBDTB. However, whereas films derived from BBDTB appear very linear, the features of films derived from $(-)$-CTXCT are at an angle in relation to the direction of propagation. This suggests that the structures formed are indeed chiral and that the chirality might be discerned at the surface. Scanning Probe Microscopy (SPM) techniques have been previously used, with some success, to establish the chirality of adsorbates. ${ }^{65-70}$ To establish that the structural uniqueness of the film was due to the chirality of the ligand, films were prepared with the other enantiomer $(+)$-CTXCT. Films prepared from the reaction of $(+)$-CTXCT with $\mathrm{Fe}^{2+}$ were, once again, very similar in structure to those derived from (-)-CTXCT.

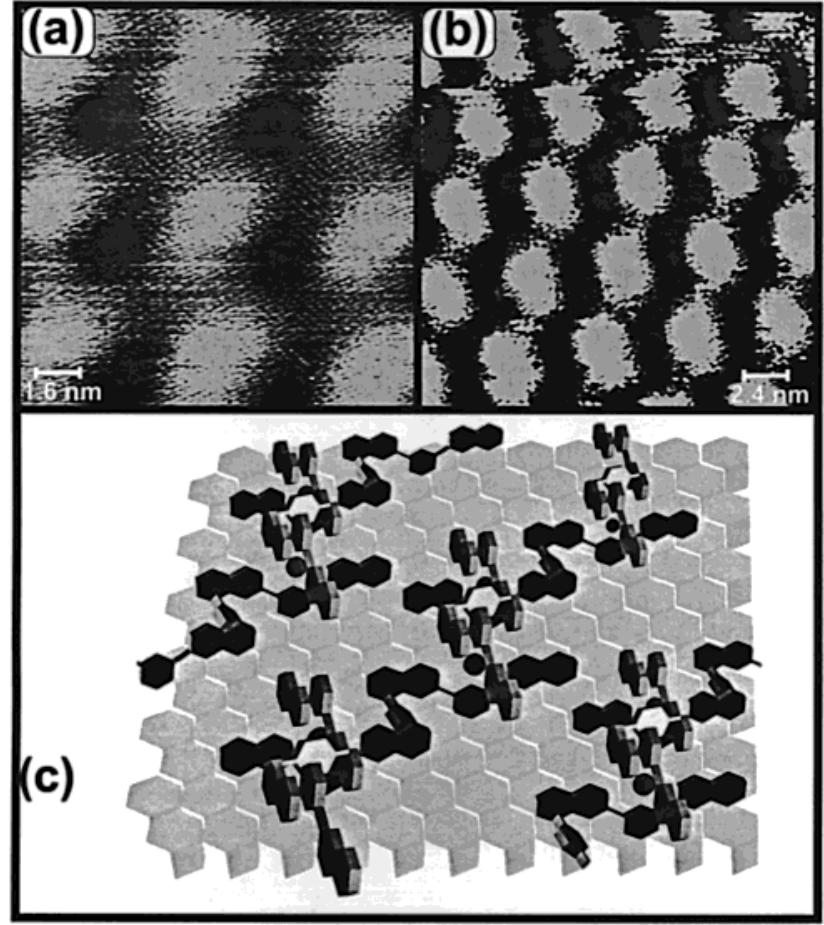

Figure 10. (a) High-resolution image $(13 \times 13 \mathrm{~nm})$ of a (-)-CTXCT/ $\mathrm{Fe}^{2+}$ film (b) High-resolution image $(19 \times 19 \mathrm{~nm})$ of a $(+)$-CTXCT/ $\mathrm{Fe}^{2+}$ film (c) Model of film derived from (+)-CTXCT/ $\mathrm{Fe}^{2+}$

However, and as expected, the rotational sense of the helical features derived from (+)-CTXCT (Figure 10b) was opposite to that of films prepared from $(-)$-CTXCT. A comparison of the images presented in Figures 10a and 10b shows that the chirality of the ligand from which the film is derived can be established by STM imaging. A model of a film derived from $(+)$-CTXCT is presented in Figure 10c, in which the origin of the angle of the features relative to the direction of propagation is clearly evident.

Electrochemical STM (ECSTM) studies of these films are currently being carried out in order to understand the effects of electrode potential and the redox state of the metals on the films' properties and structure. We believe that such studies will provide complementary information in terms of how these factors affect structure and stability of the films. Results from these investigation will be presented elsewhere.

\section{Conclusions}

We have studied the formation of well ordered films, on HOPG surfaces, via metal coordination initiated self-assembly. The films were prepared by the interfacial reaction of terpyridine containing dendrimers and bridging ligands dissolved in $\mathrm{CH}_{2}-$ $\mathrm{Cl}_{2}$ with aqueous solutions of $\mathrm{Fe}^{2+}$ and $\mathrm{Co}^{2+}$. The films appear to arise as a result of the two-dimensional packing of onedimensional strands (akin to a pearl necklace) where the repeat unit in the case of dendrimers (reacting with $\mathrm{Fe}^{2+}$ ) would ostensibly be (tpy-dend-(tpy') ${ }_{n-2}$-tpy- $\left.\mathrm{Fe}^{2+}\right)_{x}($ where tpy $=$ terpyridine that bridges (via coordination to an $\mathrm{Fe}^{2+}$ center) two dendrimer molecules and tpy $^{\prime}=$ terpyridine not coordinated to an $\mathrm{Fe}^{2+}$ center). After formation, these 1-D strands appear to self-assemble on the electrode surface forming trigonally packed structures. All of the resulting films were electrochemically active and the formal potentials were very close to those of the corresponding terpyiridne analogues. In all cases, a singular redox wave was observed suggesting the lack of any ligand mediated metal/metal interactions. The formal potentials were 
found to depend on ionic strength suggesting some charge screening effects. Values of the apparent diffusion coefficients were consistent with the electron self-exchange rates of the corresponding $\mathrm{Co}^{2+/ 3+}$ and $\mathrm{Fe}^{2+/ 3+}$ processes.

The combined STM and electrochemical studies have provided valuable insights on the formation of these highly ordered structures. In the case of dend- $n$-tpy/ $\mathrm{M}^{2+}$ films, it appears that although a truly 2-D array is likely to be more thermodynamically stable, the 1-D chains appear to be the kinetically controlled product/structure. We have also found that film formation is dependent on several factors, of which the rigidity/ rotational freedom of the ligand appears to be the dominant one. These materials appear as promising molecular building blocks for the generation of structures of deliberate architecture, and the interfacial approach employed appears well-suited for the formation of such structures and for the generation of 2-D as well as 3-D structures. Moreover, hetero-multimetallic structures of controlled composition with unique electrochemical, magnetic or optical properties could also be generated and such studies are currently being pursued.

Acknowledgment. This work was supported by the Cornell Center for Materials Research (CCMR) and the Office of Naval Research. D.J.D. acknowledges CCMR support by the R.L. Sproull Fellowship and the Ford Foundation for the Ford Fellowship. S.B. acknowledges support by the Swiss National Science Foundation.

\section{References and Notes} therein.

(1) Tsukruk, V. V. Adv. Mater. 1998, 10, 253-257, and references

(2) Service, R. F. Science 2000, 290, 1524-1525.

(3) Kalyanasundaram, K. Photochemistry of Polypyridine and Porphyrin Complexes; Academic Press: London, U.K., 1991.

(4) Matthews, O. A.; Shipway, A. N.; Stoddart, J. F. Prog. Polym. Sci. 1998, 23, 1-56.

(5) Fréchet, J.-M. J. Science 1994, 263, 1710-1715.

(6) Tomalia, D. A.; Naylor, A. M.; Goddard, W. A. III Angew. Chem., Int. Ed. Engl. 1990, 29, 138-175.

(7) Zeng, F.; Zimmerman, S. C. Chem. Rev. 1997, 97, 1681-1712.

(8) Majoral, J. P.; Caminade, A. M. Chem. Rev. 1999, 99, 845.

(9) Fischer, M.; Vogtle, F. Angew. Chem., Int. Ed. Engl. 1999, 38, 884-905.

(10) Zhao, M.; Sun, L.; Crooks, R. M. J. Am. Chem. Soc., 1998, 120, 4877-4878.

(11) Gorman, C. B.; Smith, J. C.; Hager, M. W.; Parkhurst, B. L.; Sierzputowska-Gracz, H.; Haney, C. A. J. Am. Chem. Soc. 1999, 121, $9958-$ 9966

(12) Reetz, M. T.; Lohmer, G.; Schwickardi, R. Angew. Chem., Int. Ed. Engl. 1997, 36, 1526.

(13) Chow, H. F.; Mak, C. C. J. Org. Chem. 1997, 62, 5116.

(14) Bhyrappa, P.; Young, J. K.; Moore, J. S.; Suslick, K. S. J. Am. Chem. Soc. 1996, 118, 5708-5711.

(15) Miedaner, A.; Curtis, C. J.; Barkley, R. M.; DuBois, D. L. Inorg. Chem. 1994, 33, 5482.

(16) Zhao, M.; Tokuhisa, H.; Crooks, R. M. Angew. Chem., Int. Ed. Engl. 1997, 36, 2596-2600.

(17) Valério, C.; Fillaut, J. L.; Ruiz, J.; Guittard, J.; Blais, J. C.; Astruc, D. J. Am. Chem. Soc. 1997, 119, 2588-2589.

(18) Newkome, G. R.; Moorefield, C. N.; Vögtle, F. Dendritic Molecules: Concepts, Syntheses, Perspectives; VCH: Weinheim, 1996.

(19) Newkome, G. R. Advances in Dendritic Macromolecules; JAI Press: Greenwich, CT, 1994.

(20) Balzani, V.; Campagna, S.; Genti, G.; Juris, A.; Serroni, S.; Venturi, M. Acc. Chem. Res. 1998, 31, 759-833.

(21) Bar-Haim, A.; Klafter, J. J. Phys. Chem. B 1998, 102, 1662-1664. (22) Juris, A.; Balzani, V.; Barigelleti, F.; Campagna, S.; Belser, P.; von Zelewsky, A. Coord. Chem. Rev. 1998, 85.

(23) Tully, D. C.; Wilder, K.; Fréchet, J. M.; Trimble, A. R.; Quate, C. F. Adv. Mater. 1999, 11, 314

(24) Takada, K.; Díaz, D. J.; Abruña, H. D.; Cuadrado, I.; Casado, C.; Alonso, B.; Morán, M.; Losada, J. J. Am. Chem. Soc. 1997, 119, $10763-$ 10773.
(25) Alonso, B.; Morán, M.; Casado, C. M.; Lobete, F.; Losada, J.; Cuadrado, I. Chem. Mater. 1995, 7, 1440-1442.

(26) Van Veggel, F. C. J. M.; Huck, W. T. S.; Reinhoudt, D. N. Macromol. Symp. 1998, 131, 165-173.

(27) Gorman, C. Adv. Mater. 1998, 10, 4, 295.

(28) Frey, H.; Lach, C.; Lorenz, K. Adv. Mater. 1998, 10, 4, 279-294.

(29) Bryce, M. R.; Devonport, W.; Adv. Dendritic Macromol.: Redox Active Dendrites 1996, 3, 115-149.

(30) Gorman, C. B.; Parkhurst, B. L.; Su, W. Y.; Chen, K. Y. J. Am Chem. Soc. 1997, 119, 1141-1142.

(31) Grosshenny, V.; Harriman, A.; Ziessel, R.; Angew. Chem., Int. Ed. Engl. 1995, 34, 1100.

(32) Sauvage, J. P.; Collin, J. P.; Chambron, J. C.; Guillerez, S.; Coudret, C.; Balzani, V.; Barigeletti, F.; DeCola, L.; Flamingi, L. Chem. Rev. 1996, 94, 993.

(33) Balzani, V.; Barigelletti, F.; Belser, P.; Bernhard, S.; De Cola, L.; Flamigni, L. J. Phys. Chem. 1996, 100, 16 786-16 788 .

(34) De Cola, L.; Balzani, V.; Barigelletti, F.; Flamigni, L.; Belser, P.; Bernhard, S. Recl. Trav. Chim. Pays-Bas 1995, 114, 534-541.

(35) Belser, P.; von Zelewsky, A.; Frank, M.; Seel, C.; Vögtle, F.; De Cola, L.; Barigelletti, F.; Balzani, V. J. Am. Chem. Soc. 1993, 115, 4076. (36) Mansfield, M. L. Polymer 1996, 37, 3835-3841.

(37) Hudson, S. D.; Jung, H. T.; Percec, V.; Cho, W. D.; Johansson, G.; Ungar, G. Science 1997, 278, 449-451.

(38) Hamers, R. J. J. Phys. Chem. 1996, 100, 13 103-13 120

(39) García, V. J.; Martinez, L.; Briceño-Valero, J. M.; Schilling, C. H. Probe Microscopy 1997, 1, 107-116.

(40) Griffith, J.; Grigg, D. A. J. Appl. Phys. 1994, 74, R83.

(41) Ramirez-Aguilar, K. A.; Rowlen, K. L. Langmuir 1998, 14, 25622566.

(42) McWhinnie, W. R.; Miller, J. D. Adv. Inorg. Chem. Radiochem. 1969, 12, 135-215.

(43) Storrier, G.; Takada, K.; Abruña, H. D. Langmuir 1999, 15, 872884 .

(44) Takada, K.; Storrier, G.; Morán, M.; Abruña, H. D. Langmuir 1999, $15,7333-7339$

(45) Bernhard, S.; Takada, K.; Díaz, D. J.; Abruña, H. D., submitted.

(46) Potts, K. T.; Usifer, D. A.; Guadalupe, A.; Abruña, H. D. J. Am. Chem. Soc. 1987, 109, 3961-3967.

(47) Constable, E. C.; Cargill Thompson, A. M. W. J. J. Chem. Soc., Dalton Trans. 1992, 3467-3475.

(48) Fife, W. K. J. Org. Chem. 1983, 48, 1375-77.

(49) Clavillier, J.; Armand, D.; Sun S. G.; Petit, M. J. Electroanal. Chem. 1986, 205, 419 .

(50) Nam, A. J.; Teren, A.; Lusby, T. A.; Melmed, A. J. J. Vac. Sci. Tech. 1995, 13, 1556-1559.

(51) Díaz, D. J.; Abruña, H. D., unpublished results.

(52) Buttry, D. A.; Anson, F. C. J. Am. Chem. Soc. 1983, 104, 685689.

(53) Beebe, T., \& Clemmer, C. Science 1991, 251, 640-642.

(54) Chang, H., \& Bard, A. J. Langmuir 1991, 7, 1143-1153.

(55) Kuwabara, M.; Clarke, D. R.; Smith, D. A. Appl. Phys. Lett. 1990, $56,2396-2398$

(56) Liu, C.-Y., Chang, H.; Bard, A. J. Langmuir 1991, 7, 1138-1142.

(57) Xhie, J.; Sattler, K.; Ge, M.; Venkateswaran, N. Phys. Rev. B. 1993 $47,15,835-15,841$.

(58) Ouseph, P. J. Phys. Rev. B. 1996, 53, 9610-9613.

(59) Rong, Z. Y.; Kuiper, P. Phys. Rev. B. 1993, 48, 17 427-17 431.

(60) Patrick, D. L.; Beebe, T. P., Jr. Surf. Sci. Lett. 1993, 297, L1191121

(61) Cee, V. J.; Patrick, D. L.; Beebe, T. P., Jr. Surf. Sci. 1995, 329, $141-148$.

(62) Díaz, D. J.; Storrier, G. D.; Bernhard, S.; Takada, K.; Abruña, H. D. Langmuir 1999, 15, 7351-7354.

(63) Sheiko, S. S.; Eckert, G.; Ignat'eva, G.; Muzafarov, A. M.; Spickerman, J.; Räder, H. J.; Möller, M. Macromol. Rapid Commun. 1996, $17,283-297$.

(64) Giancarlo, L. C.; Flynn, G. W. Annu. Rev. Phys. Chem. 1998, 49 , 297-336.

(65) Hermann, B. A.; Hubler, U.; Jess, P.; Lang, H. P.; Guntherodt, H. J.; Greiveldinger, G.; Rheiner, P. B.; Murer, P.; Sifferlen, T.; Seebach, D. Surf. Int. Anal. 1999, 27, 507-511.

(66) Walba, D. M.; Stevens, F.; Dyer, D. J.; Parks, D. C.; Clark, N. A.; Wand, M. D. Enantiomer 1996, 1, 267.

(67) Lellek, V.; Stibor, I. J. Mater. Chem. 2000, 10, 1061-1073.

(68) De Feyter, S.; Gesquiere, A.; Grim, P. C. M.; De Schryver, F. C. Langmuir 1999, 15, 2817-2822.

(69) Bohringer, M.; Schneider, W. D.; Berndt, R. Angew. Chem., Int. Ed. 2000, 39, 792.

(70) Bohringer, M.; Morgensten, K.; Schneider, W. D.; Berndt, R. Angew. Chem., Int. Ed. 1999, 38, 821. 